\title{
"There Are Many Social Evils...and Only We Can Cure It": A Thematic Content Analysis of Privileged Indian Youth's Perspective on Social Issues
}

Sriya Bhattacharyya

\author{
Boston College \\ Jasleen Kaur \\ Boston College \\ Gabriel Corpus \\ Palo Alto University
}

\author{
M. Brinton Lykes \\ Boston College \\ Martin Heesacker \\ University of Florida
}

\begin{abstract}
This study aimed to investigate how socioeconomically privileged students at a private school in India understood social issues in their communities, and it explored whether their understanding of and discourse about working against social and economic oppression changed after they took a field trip to a nearby under-resourced village. The sample included 75 youth from high-income backgrounds in Bhubaneswar, India, most of whom reported never having spent time in a poverty-stricken village. Students responded in writing to reflection prompts before and after the field trip. Participants' responses were thematically coded to capture their perspectives of social injustice and ideas of change. A codebook of participants' reflections was then developed, consisting of thirty-five themes and seven overarching domains: (1) positionality; (2) discrimination; (3) structural issues; (4) village-level issues; (5) strategies for problem solving; (6) experiences of helping; and (7) reasons for or barriers to problem solving. Descriptive frequencies revealed the prevalence of themes before and after the field trip. Implications and limitations of the study and directions for future research on enhancing awareness of privilege and social oppression are discussed.
\end{abstract}

Keywords: social justice education; immersion trips; youth; privilege; poverty 


\section{Introduction}

International development initiatives in India often focus on providing resources to the marginalized, with little analysis of systems and structures that maintain marginalization (International Development Research Centre, 2007). Liberation psychology calls psychologists to critically examine and intervene at the structural levels of oppression (Moane, 2003). In India, interventions aimed at reducing injustice rarely include those who hold or soon will hold material power, in this case, privileged Indian youth. In this paper, privileged youth are those who benefit from systemic, unearned advantage through economic class, social class (McIntosh, 1988), and specifically in the Indian context, caste (Bhattacharyya, Woods, \& Lykes, 2017). This study focused on intervening with socially and economically privileged Indian youth, the very people most likely to grow up to control critical resources, systems, and structures in India. It also explores novel strategies being utilized to promote social justice advocacy in some privileged schools and describes an immersion intervention, in this case, a field trip to an under-resourced village, designed to foster social justice engagement in privileged students. Further, we describe efforts to understand how these students conceptualized issues related to social and economic privilege and marginalization, and whether student understanding differed after their poverty exposure experience and after reflecting on that experience. Implications for practice and future research in India are discussed.

\section{Liberation Psychology Framework}

A psychology of liberation develops critically and historically contextualized psychological theories and practices from the perspective of "the people," wherein marginalized voices contribute to developing a community's vision (Moane, 2003). In India, development initiatives are often guided by outsider perspectives on social issues and solutions. Instead, by accompanying the poor and oppressed, a psychology of liberation calls psychologists to "create relationships among groups of people and transform society by making people aware of dehumanizing social inequities, and accompanying them in processes through which they analyze the causes of their marginalization" (Lykes \& Sibley, 2014, p. 211). The current research aims to better understand privileged Indian youth's understanding of social issues by seeing how their perspectives qualitatively shift after an immersion field trip to an under-resourced village in their community. One assumption we want to explore is whether persons that experience power or oppression can change based upon context. In this study, Indian youth are seen to have had little voice or representation in psychological literature. However, within their communities, the youth in this study are, for the most part, privileged. Facilitating awareness of social issues and critical consciousness development is important to do with these youth so they can be a part of a liberatory societal transformation. Liberation psychology calls psychologists to critically examine the political, economic, and cultural forces that cause oppression. This study takes one step in attending to the factors that contribute to oppression by engaging privileged youth in an immersion project in a small community in rural India.

\section{Immersion Strategies for Promoting Social Justice Awareness Among Students}

In the educational setting, international educational institutions have implemented immersion programs with the intent of increasing socio-political involvement and social justice awareness amongst their students (Bowman, Brandenberger, Mick, \& Smedley, 2010; Choi, VanVoorhis, \& Ellenwood, 2015; Cordero \& Rodriguez, 2009; Panwar et al., 2014). While immersion programs can vary based on duration, program structure, field of study etc., the significant factors of immersion programs discussed provide students the opportunity to learn

(c) 2018 Bhattacharyya, et al. Free to copy and share for education and scholarship under a Creative Commons Attribution NonCommercialNoDerivatives 4.0 License. 
about how others live, the social issues that impact them through involvement in the field, and the space to reflect upon their experiences of immersion individually and in groups (Choi et al., 2015; Cordero \& Rodriguez, 2009). In the current study, immersion is defined through this lens.

Published studies focused on U.S. university and graduate education-level students engaging in an immersion program overseas (e.g., South Africa, Puerto Rico) demonstrate that immersion experiences foster cross-cultural learning for students when given the opportunity to engage in self-reflection through crosscultural interactions and journaling (Choi et al., 2015; Cordero \& Rodriguez, 2009). Choi et al. (2015) focused on U.S. students participating in a 14-day immersion program in South Africa and found that through this process students demonstrated an increased awareness around social justice issues such as "...poverty, lack of educational resources, weak social infrastructure, employment inequality, and racial segregation” (p. 253). Furthermore, an increase in students' awareness around social issues and their own role in relation to these issues appeared to effect change in their behaviors (Choi et al., 2015; Cordero \& Rodriguez, 2009), including the development of advocacy behaviors such as lobbying for change (Cordero \& Rodriguez, 2009) and helping the homeless or donating to charities on a local level (Choi et al., 2015).

While immersion programs are practiced at the university level due to their ability to instill social awareness and social advocacy (Bowman et al., 2010; Choi et al., 2015; Cordero \& Rodriguez, 2009), there are limited studies focused on school-age students participating in immersion studies. There are, however, schoolbased social justice initiatives practiced at the grade school and high school levels in India (Ashley, 2006; Jessop, 2001), illustrating the school's role in addressing social injustices within its community. In many instances, a school's engagement in any social justice oriented work in its community marks the school as an agent of change in its community. This was found to be especially true for affluent Indian schools that implemented social justice programs (Ashley, 2006; Jessop, 2001). Furthermore, findings from multi-country studies, including India, suggested that both mandatory and optional social justice initiatives in high school and at a university led to higher participation in general volunteering (Brudney et al., 2010), demonstrating the long-term effects of these initiatives on a social level.

\section{Immersion Intervention via School Field Trip}

While international research has demonstrated immersion initiatives in educational settings to be useful in social justice awareness development among students, much of the literature explores immersion experiences that are long-term, over the span of a school semester or longer (Choi et al., 2015; Cordero \& Rodriguez, 2009; Panwar, et al., 2014). The literature is limited to assessing the effects of brief immersion interventions on social justice awareness, specifically using field trips to sites such as under-resourced villages in rural areas. This is especially relevant in India, the country with the largest population of people experiencing extreme poverty in the world (302 million) with 73.2\% (221 million) of its poor living in rural areas (Mehta, Shepherd, Bhide, Shah, \& Kumar, 2011). While exposure to poverty occurs on a day-to-day basis in India, as these statistics indicated, exposure is not synonymous with immersion. Although many Indian residents see poverty and other social injustices daily, they are not required to give attention to these issues as they would in an immersion experience, which includes engagement with those impacted by social injustice and critical thinking or reflection upon the experience. Heybach (2015) addressed the desensitization and "anesthetization" to visual imagery of social injustices among her students, in a U.S. undergraduate college setting, as responses to the constant flooding with images of mass violence, war, tragedy, etc. In this way, residents in India cannot be expected to critically think about social injustices in their communities and country as passersby, as daily images of social injustices may trigger feelings of desensitization (Heybach, 2015). Sites of economic injustice, such as under-resourced communities in rural India can provide urban youth ways to engage in these social injustices directly with the aim of building awareness of the struggles of marginalized people. 


\section{Privileged Indian Youth as Agents of Change}

Social justice research in India has focused primarily on social engagement (Ashley, 2006; Jessop, 2001) with insufficient research exploring Indian youth's beliefs surrounding issues impacting their communities. Youth's attitudes and social beliefs preclude how they may engage in social and political change (Perrin, Bhattacharyya, Snipes, Hubbard, Heesacker, Calton, Perez, \& Lee-Barber, 2013), and therefore may provide insight into social justice engagement for this population.

Current research indicates that Indian youth are disillusioned by the political system, which may facilitate their involvement in social change. As such, they tend to engage in public advocacy through employment with NGOs and involvement in community outreach (Ilavarasan, 2013). This may be the result of the Indian political system's well-known reputation for corruption (Pring, 2017). Furthermore, a recent study conducted by Acharya et al. (2010) utilized a representative sample of Indian youth and reported $80 \%$ of young men and $75 \%$ of young women in the sample did not believe the political process would make positive change in their communities, regardless of which political party was elected into office. Despite these profoundly negative views of the political system, over $80 \%$ of this sample reported viewing the political process in India as fair, with no fear or pressure when voting in elections (Acharya et al., 2010). Recent Indian elections have shown increased voter turnout. Election data indicated a $66.4 \%$ youth voter turnout in the 2014 Indian elections, the highest in any Indian election to date (Sharma, 2014). This recent surge in political engagement may reflect Indian youth's desire for political change.

Privileged youth, identified in this paper as those holding economic and social class advantages, have a unique role in combating oppression as upcoming leaders and professionals in their communities (ThomsonMiller \& Feagin, 2007). These youth have access to material and social resources that will keep them in high social ranking as they enter adulthood, which means they will likely hold positions of power in their later years. As allies to the oppressed, privileged youth can invest their privilege for social good (Perrin et al., 2013), which potentially can have a large impact on dismantling oppression in the future. Therefore, consciousness-raising among the privileged is critical for a liberatory social transformation (Case, 2013).

Unfortunately, little literature has examined the ways in which Indian youth experience and understand social issues. To help address this absence in our knowledge base, the current study was designed to examine whether engaging privileged Indian youth in their greater communities may coincide with their increased interest in and more thoughtful analysis of social justice issues. Specifically, this study aimed to answer the following questions:

1. How do privileged Indian students understand social issues in their communities?

2. Will Indian students' understanding of and discourse about working against social and economic oppression change after they take a field trip to a nearby under-resourced village?

Though India does not systematically implement national immersion educational schemes, by assessing the link between individual school programs and youth's social justice awareness development the results may help to guide researchers and educators in choosing interventions to engage privileged students in political and social justice issues. As such, this study examined the link between a one-time field trip to an under-resourced village and changes in participants' awareness about injustice and their propensity to engage in social change.

\section{Methods}

\section{Participants}

The sample consisted of students in social studies classes at a private English-medium high school in Bhubaneswar, India, where the first author was a research fellow. The project included 75 economically privileged Indian youth whom each participated in a field trip to an under-resourced rural village as a part of his or her 
social studies class. Participants included 53 males (70.7\%) and 22 females (29.3\%) who were 12-16 years of age $(\mathrm{M}=14.49, \mathrm{SD}=8.44)$. Participants identified as Hindu (97.3\%), Muslim (1.3\%), or not believing in a specific religion (1.3\%). All participants were from a 'General' (upper-caste) background. They received credit for their social studies class and a certificate of participation for engaging in the study. The University of Florida IRB approved this study as research of archival data from students' schoolwork.

\section{Field Trip Experience}

During the field trip, participants were immersed in a nearby rural village community for approximately five hours. The village was significantly less resourced than the boarding school the participants lived in. For example, there was irregular electricity, no running water, limited healthcare services, and the village children had no school supplies. Houses in the village were made of mud and straw, juxtaposed to the air-conditioned, brand new building where the participants attended school down the road. Despite being in the same geographic locality, the circumstances in the village were drastically different from participants' daily surroundings. The field trip was organized by the high school social studies teacher who had a personal connection to the village and the first author. Social science teachers, whom all had at least bachelor's level degrees in humanities, were selected as chaperones. The chaperones met with the social studies teacher and the first author to understand the purpose of the field trip and obtain instructions for the students. Participants were broken into 4 groups when visiting the village and were chaperoned by their teachers. As the focus of the field trip was to learn about inequality and what role people with privilege have in resolving it, each participant was given these instructions verbally and in writing: "We will be going to visit a village. Observe the village activities carefully. Be sure to notice social problems faced by the villagers. In your notebook, take notes on the problems you see. Think of ways you, personally, could help them, and take notes in your notebook about what specific actions you could take to help them. Please be as personal and specific as possible. These notes will be important to you later."

At the village, all of the groups had an opportunity to visit the village panchayat (government), hospital and local doctor, school classrooms and students, and village merchants. The participants were able to ask questions and dialogue with villagers, and kept notebooks of their observations. Upon return, depending on their teacher, some participants reflected on their experience by completing a writing assignment for their social studies class that asked them to reflect on their experience and what they learned in the village. Other participants were asked by their teachers to create and put on a theatrical play for the school to convince peers about their role and the importance of helping others. Due to the extensive amount of data collected during this project, data obtained from participants' written and theatrical reflections will be shared in a future paper.

\section{Data Collection and Instrumentation}

Participants responded in writing to three open-ended prompts about social issues, ideas about and perceived responsibilities towards social injustice, and past experiences with helping others both a week prior to and one day after the field trip. All prompts and responses were written in English. To prevent inadvertent inclusion of preconceived categories, the researchers used open-ended prompts:

1. What do you think is unfair about society? Do you see any problems that could be changed?

2. Do you think you have a role in helping society? If so, what is your role?

3. Have you done anything in your past to help others who are less fortunate? (If so, explain. If not, why not?)

Responses to the three questions were transcribed from hand-written responses to typed digital files by research assistants in the U.S. Participants did not have an opportunity to re-check their response transcriptions. Transcriptions were then inductively coded to create a codebook. 


\section{Analysis}

\section{The Development of the Codebook}

A conventional content analysis (Hsieh \& Shannon, 2005) utilizing inductive thematic coding (Charmaz, 2014) was used to analyze the data from the above prompts. A codebook was developed from the qualitative analysis to obtain the presence of codes across the data before and after the field trip intervention.

In content analysis, the participants' narratives are condensed into content-related categories, and when the participants' words are classified into similar categories, they reflect shared meanings (Elo \& Kyngas, 2007). Qualitative content analysis focuses on the interpretation of text data through the identification of themes or patterns that emerge directly from the narratives of the participants, and a systematic process of coding (Hsieh \& Shannon, 2005). As such, this approach allows for the researchers to gain in-depth understandings of participants' experiences, and the meanings and context that are accompanying these experiences, without the imposition of pre-existing categories (Downe-Wamboldt, 1992; Hsieh \& Shannon, 2005).

Pre-intervention and post-intervention data were analyzed using Charmaz's (2014) in vivo coding strategy. The interview transcripts were coded by each member of the data analysis team (e.g., the first, second, and third authors). The team consisted of one doctoral and two master's level counseling psychology students at Boston College with experience and coursework in graduate level qualitative research. Two senior doctoral-level faculty members, one in community psychology and the other in counseling psychology, rigorously reviewed the coding and consulted extensively on the study design and analyses. The researchers immersed themselves independently in reading the transcriptions several times, carefully attending to the participants' responses word for word. The first and second authors carried out first, second, and third-level coding (described below). They identified phrases, words, or sentences in the transcripts, preserving the participants' original words. These first-level codes were selected because of their significance vis-à-vis the overarching research question regarding youths' awareness of injustice and propensity to engage in social change.

The second-level codes emerged through an inductive process of collapsing codes into categorical themes. These themes continued to be named using participants' original words. Finally, the third-level codes were derived through analysis of the relationships between the second-level codes, and are the domains presented in the final codebook and analysis (Charmaz, 2014). Discussion and deliberation occurred between the first, second, and third authors to reach consensus as they developed the third-level domains, and subsequently, as they defined the themes in the codebook.

Two additional coders, the third author and a research assistant, subsequently coded the data using this codebook. The third author coded the full data set using the codebook developed by the first and second author, and added additional codes, which emerged through conversations and eventual consensus with the first author. The research assistant blind coded the dataset with the fully completed codebook. To ensure accurate use of the codebook, the research assistant only rated 10 transcripts at a time and asked the first author for clarification if necessary. This led to the achievement of at least 70\% agreement between the research assistant and the first author across all 35 codes for both pre- and post-intervention transcripts. This process assured accuracy and consensus of themes and domains in the data.

With respect to self-reflexivity, as indicated in recent guidelines for qualitative studies (Morrow, 2005; Yeh \& Inman, 2007), the researchers engaged in regular discussions concerning biases and assumptions throughout the study that may have influenced the process of data interpretation and codebook development. Of the authors involved in the coding process, two identify as South Asian Americans, and one identifies as Filipino American. The two supervising authors identify as White American. They discussed the potential influence of their cultural backgrounds on the research process and the participants' responses to the interviews. Specifically, the two authors discussed their own backgrounds as privileged South Asians who live in the United States and 
have visited India regularly for work or to see family. The non-South Asian authors engaged in open discussions of their understanding of Indian culture and leaned on the two South Asian American authors for insight into cultural issues. The authors aimed to center participants' narratives in data analysis and interpretation (Strauss \& Corbin, 1998). The participants' words are reflected in the reporting of the findings as we provide quotes from the transcripts.

\section{Results}

The data analysis revealed that participants explored seven general domains that will be detailed in the following sections. These domains include: positionality, discrimination, structural issues, village level issues, strategies for problem solving, experiences of helping, and reasons for problem solving. Within each domain, various themes developed as they represented a common thread that participants reported. We will present quotes that illustrate the themes as well as provide frequencies of the themes seen in participants' responses. These frequencies are represented as both pre (t1) and post (t2) intervention.

\section{Positionality}

The first domain reflects how participants positioned themselves in relation to those they identify as affected by social issues and problems. Many participants approached discussing social issues by aligning themselves with a perspective of either the collective, the other, or the inquisitive outsider. Through this perspective, the participants delved into their understanding of societal issues.

Collective $(\mathbf{t} 1=36, \mathbf{t} 2=\mathbf{2 8})$. The participants aligned themselves as a part of the greater society in which problems exist.

"Yes, I do have a role in helping the society as a good citizen I could help my society to be the best because I love my society and the people of the society those who help each other." (Female, Age 15, t1)

“There are many social evils in the society like gender discrimination, untouchability, caste systems, etc. These all are created by us and we can only cure it." (Male, Age 13, t2)

Otherness $(\mathbf{t} \mathbf{1}=\mathbf{4 1}, \mathbf{t} \mathbf{2}=\mathbf{4 6})$. The participants separated themselves from those impacted by the problems in society. Some participants took the role of expert on the experiences of others.

"We can change many problems like by making understand the people about the problem." (Female, Age $16, \mathrm{t} 1)$

"Yes I have donated a few of my things to the poorer society and participated in activities to help the poor through my school. I have been motivating others to help the unprivileged society I have not gotten many opportunities to help them but whenever I see a needy I always help them by some means." (Male, Age 16, t2)

Inquisitive outsider $(\mathbf{t} \mathbf{1}=\mathbf{0}, \mathbf{t} \mathbf{2}=\mathbf{4})$. While this theme did not have a great presence in the data, few participants differentiated themselves from those affected by societal problems and also sought some expertise on the topic from those impacted first hand.

"We should go for research work and learn about the people so that we actually understand what is important to the people."(Female, Age 15, t2) 
Understanding problems $(\mathbf{t} 1=5, \mathbf{t} 2=\mathbf{9})$. Some participants discussed how they understand, know, and ask about the problems others face.

"Why this thing happen in Society? In constitution there is a word 'Equality', but nobody follows it. As in French revolution, the only 3rd estate has to pay the taxes which are not rich. I feel this all things are unfair." (Female, Age 15, t1)

"If we don't do it, we should at least try to solve the problem, or we should take advice from any experts or from our elders and then try to solve the problems." (Male, Age 13, t2)

\section{Discrimination}

The second domain explores the various forms of discrimination identified by participants. These forms of discrimination are depicted as issues within the society that pose a hardship for individuals.

Caste discrimination $(\mathbf{t} \mathbf{1}=\mathbf{2 7}, \mathbf{t} \mathbf{2}=\mathbf{1 8})$. Participants identified problems related to the caste system present in India. Some specific castes mentioned by participants include SC, ST, OBC, Dalit, and untouchable. Some participants also framed solutions as targeting untouchability or the caste system.

"It is inequality among the lower caste and upper caste and poverty is the big problem." (Female, Age $15, \mathrm{t} 1)$

“(1) People of lower castes are not given equal chances. (2) People of lower castes are discriminated. (3) People of lower castes are not [given] equal rights." (Male, Age 13, t2)

Gender discrimination $(\mathbf{t} \mathbf{1}=\mathbf{2 2}, \mathbf{t} \mathbf{2}=\mathbf{2 0})$. Participants referred to problems related to gender inequality or framed solutions in targeting gender injustices. Gender inequality was addressed as the differential treatment of men and women or girls and boys, especially in the way of boys or men receiving greater privileges than girls or women.

"Males are given more privileges but females are not" (Female, Age 14, t1)

"I can raise awareness among the people regarding different issues like gender discrimination, etc." (Male, Age 13, t2)

Religious discrimination $(\mathbf{t} 1=5, \mathbf{t} 2=5)$. Some participants identified religious discrimination as an issue in society and explored solutions to religious-based injustice. Specifically, the idea of individuals from different religions being unable to marry was identified as an injustice.

"It is inequality among Hindu and Muslim ... it's the big problem." (Male, Age 15, t1)

"Religious discrimination example two people from different religions cannot marry each other." (Female, Age 15, t2)

Economic discrimination $(\mathbf{t} 1=35, \mathbf{t} 2=\mathbf{2 7})$. Many participants discussed economic discrimination in society as a great injustice. Specifically, they referred to problems related to economic differences (class, rich, poor, monetary resources) or framed solutions as targeting class injustices. Within this theme, caste was as brought up due to the parallels of caste and economic status in Indian society.

"Their attitudes, behaviour towards each other or the attitudes, the behaviour of rich for the poor people. 
Yes, I think that there should be a balance between rich and poor people. For this the poor people should be educated." (Female, Age 15, t1)

"Most of the poor people are not allowed to go to the temples where the rich people go." (Female, Age $15, \mathrm{t} 2)$

Age discrimination $(\mathbf{t} 1=5, \mathbf{t} 2=3)$. Participants referred to discrimination based on age (e.g., between seniors \& juniors/ragging, parents/elderly \& children, etc.).

"I think in which society I live people are not given a chance to participate only the seniors are likely to participate. They are discouraged by the seniors." (Male, Age 15, t1)

“There is no respect for the elders. All people should be treated equally." (Female, Age 14, t2)

Sexual orientation discrimination $(\mathbf{t} 1=\mathbf{0}, \mathbf{t} 2=2)$. Few participants identified discrimination endured by individuals who identify as gay or homosexual. These participants referred to the illegality of homosexuality in the Indian justice system.

"Homosexuality is noted as a crime." (Female, Age 15, t2)

"Becoming gay is illegal." (Female, Age 15, t2)

Unspecified discrimination $(\mathbf{t} 1=\mathbf{2 4}, \mathbf{t} \mathbf{2}=\mathbf{2 8})$. There were participants who generally referred to discrimination or inequality in India but did not specify types of discrimination. Some of these participants approached general discrimination as a barrier to societal progression through the lens of problem-solving.

"There are too many problems in the world, and the basic thing is we can't change the world or our society." (Female, Age 15, t1)

"Yes, I see many problems that are to be changed/like there should be any discrimination injustice in the society." (Male, Age 13, t2)

\section{Structural Issues}

The third domain addresses issues within the society that are based on structure and organization, affecting the quality of life of individuals. These structural issues range from individuals having access to clean water and sanitation to access to education. Also, explored within this domain are structural issues that participants felt the government was responsible for or has a hand in improving such as corruption within the government, increasing systemic resources like employment opportunities, and addressing human rights issues.

Basic needs $(\mathbf{t} 1=\mathbf{1 3}, \mathbf{t} 2=\mathbf{2 3})$. The first theme refers to individuals lacking the basic amenities needed for survival (water, food, shelter, clothes, \& employment). Participants addressed the issue of basic needs as an identified problem in society and formed solutions in how to increase access to basic needs. Some participants used specific examples from their field trip in identifying the lack of basic needs they witnessed first-hand in the village.

"India, the land of the common man, has the major problem of poverty. People are poor; they don't always get their necessities." (Male, Age 13, t1)

"Helping the people to get food. Helping the people to get proper employment. Helping the people to get a proper living place." (Male, Age 14, t2) 
Sanitation $(\mathbf{t} 1=\mathbf{1 0}, \mathbf{t} 2=\mathbf{1 3})$. Some participants identified a lack of cleanliness, sanitation, or hygiene as a pressing issue in society. The issue of sanitation may address water sanitation, access to toilets, liter in the streets, or many other concerns present within Indian society.

"Keeping my society clean, not waste water... Like if nobody will throw paper, plastic bags, etc. on roads at Mumbai than [then], there would not be a flood there." (Male, Age 15, t1)

"Yes, we must see that there is proper sanitation in our society and it is kept clean." (Male, Age 15, t2)

Illiteracy/lack of education $(\mathbf{t} 1=\mathbf{1 9}, \mathbf{t} 2=\mathbf{2 5})$. Participants identified illiteracy and lack of education as an issue. There was an increase in participant identification of illiteracy/lack of education post-field-trip intervention. Some participants referred to their exposure to illiteracy in the village, and some participants found illiteracy to be social injustice.

"Girls face many problems. They don't get an education, and some are not even literate. Many are homeless and as they are illiterate no occupation." (Female, Age 15, t1)

"The main problem that could be changed is illiteracy." (Female, Age 14, t2)

Crimes $(\mathbf{t} 1=\mathbf{1 0}, \mathbf{t} \mathbf{2}=\mathbf{1})$. There were some participants who found people involved in crimes (e.g., stealing, murder, and kidnapping) as a problem in society. This theme was much less represented post field trip exposure.

“There are many unfair activities going on in our society like stealing, murdering, kidnapping, etc." (Male, Age 14, t1)

“There is no unity amongst the people. People are killing each other." (Female, Age 14, t2)

Lack of systemic resources $(\mathbf{t} 1=\mathbf{1 6}, \mathbf{t} 2=37)$. Participants identified systemic issues like employment and health services as prevalent in society. Some participants also discussed long-term strategies of helping or improving this lack of resources. The presence of this theme increased following village field trip.

"The unfair thing is that the stronger always get to enjoy more opportunities but the needy people are left behind. The government should introduce new policies for the poor." (Male, Age 15, t1)

“Giving job opportunities to poor." (Female, Age 14, t2)

Corruption/not working government $(\mathbf{t} 1=16, \mathbf{t} 2=\mathbf{1 8})$. Participants referred to corruption within systems or a lack of action from the government as the source of societal problems or a barrier to overcoming these problems (e.g., need for new policies from the government).

“The Indian government does not do anything to help at all." (Male, 14, t1)

"From my view, many people are corrupt in this society; the government is also corrupt and it could only be solved by the government." (Male, Age 14, t2) 
Human rights $(\mathbf{t} 1=\mathbf{6}, \mathbf{t} \mathbf{2}=\mathbf{1 8})$. Participants referred to groups of people not having access to rights such as issues of child labor or child marriages, and others offered solutions as to obtaining rights for others. This was a theme that increased in presence post field trip intervention.

"In India, the children who are less fortunate are sent as bonded labour to other parts of India to work in very harsh conditions. The industries that they are sold to don't give them a proper place to stay, eat or anything." (Male, Age 14, t1)

"I think there are many unfair things about society like, discrimination, child rights and the rights for the poor people ...inequality and the rights which the poor/and old people are not getting, etc." (Female, Age 14, t2)

\section{Village Level Issues}

The fourth domain is comprised of participant-identified problems encountered while visiting the village "Madhuban." Participants referred to a variety of problems such as unemployment, medical-related issues, lack of infrastructure in the village, and access to food and water.

Employment $(\mathbf{t} \mathbf{1}=\mathbf{0}, \mathbf{t} 2=\mathbf{3})$. Some participants described problems relating to jobs, vocation, and/or unemployment.

"When we went to the village Madhuban we find lack of employment there." (Male, Age 14, t2)

Education $(\mathbf{t} 1=\mathbf{0}, \mathbf{t} 2=\mathbf{2 1})$. Many participants discussed the problems they saw in the village school. Specifically, they referred to problems related to lack of schools, and insufficient educational facilities and resources available to the children.

"There were many problems of the village which could only be solved by the government. In 4 villages there was only 1 hospital and 3 small schools which was not sufficient for the children over there." (Male, Age 16, t2)

Medical $(\mathbf{t} \mathbf{1}=\mathbf{0}, \mathbf{t} \mathbf{2}=\mathbf{1 0})$. Some participants referred to the problems in the village related to medical facilities and corresponding resources. In most cases, participants described the spaces used for attending to patients and the lack of trained professionals.

"The hospital of the village was very small. The hospital which was there that was only for minor injuries. There were no well-trained doctors. The medical shop was $1.5 \mathrm{~km}$ away from the hospital. There should be more well-trained doctors, and the hospital should have modern facilities." (Male, Age 16, t2)

Infrastructure $(\mathbf{t} \mathbf{1}=\mathbf{0}, \mathbf{t} \mathbf{2}=\mathbf{2 4})$. Many participants referred to problems related to the electrical, drainage facilities, and amenities in the village. Participants referenced the ways in which infrastructure made life difficult for the people they saw living in the village.

"The life was too hard for them and no electricity, no proper drainage system and many more small factors which the people were having." (Male, Age 16, t2)

Food $(\mathbf{t} 1=\mathbf{0}, \mathbf{t} \mathbf{2}=\mathbf{2})$. While not many, some participants talked about the lack of food in India and its poor quality.

"The children who are riding [writing] in that school they are not getting good education, they are not getting proper food to eat, they are not getting good dress to wear." (Male, Age 15, t2) 
Water $(\mathbf{t} \mathbf{1}=\mathbf{0}, \mathbf{t} \mathbf{2}=\mathbf{7})$. Some participants referred to water issues in Madhuban village, specifically the quality of water that they saw.

“The water was so poor over there and was not fit to drink." (Male, Age 16, t2)

\section{Strategies for Problem Solving}

The fifth domain explores various approaches participants suggested to resolve the issues described in the other domains. Participants reported a wide variety of strategies to solving problems ranging from donating resources to the less fortunate to spreading awareness about social issues and needs.

Giving/donating $(\mathbf{t} 1=\mathbf{4 5}, \mathbf{t} \mathbf{2}=\mathbf{4 3})$. Many participants described temporary strategies for helping related to giving, donating clothes, food, shelter, money or their time.

"Yes, I have helped the less fortunate that I have given money to poor to buy the crackers in Diwali and helped old people by doing their work which they cannot do." (Male, Age 14, t1)

"I can help the society by donating money to the poor ones. I can also provide shelter to them... I can also provide food to the poor ones." (Male, Age 14, t2)

Access to structural opportunities $(\mathbf{t} 1=\mathbf{8}, \mathbf{t} 2=\mathbf{2 7})$. Participants also discussed ways of helping that involved long-term strategies targeting ingrained systemic or structural barriers that lead to differential access to resources. Specifically, participants would recommend improvements that would help employment, health services, and general rights.

"Once there was a water shortage in the society's tube well. I saw the problem two days before, but no one complained about it. So I told my parents to complain about it to the water stations, and they gave a nice scolding to them \& the next day water was there." (Male, 15, t1)

"I would like to make an orphanage for the orphan people and a hospital in my village for the people of my village and also a school for them. I will make a company in which I will keep some of the people to work there. I will also provide some food in the small village near my village, and I will make a better road, and I will try my best to help the people of my village and other how much I can." (Male, Age 14, t2)

Access to literacy and educational opportunities $(\mathbf{t} 1=\mathbf{1 5}, \mathbf{t} 2=\mathbf{2 2})$. Other long-term strategies that participants suggested specifically targeted increasing literacy and access to education. Participants discussed how this could be done through teaching or encouraging more people to go to school.

"Yes, I think I have a role in helping society by making the children literate. As they can move forward in their life by being literate." (Female, Age 15, t1)

"We will help them by giving them education as well as proper studies." (Female, Age 14, t2)

Conservation/environment $(\mathbf{t} 1=\mathbf{2}, \mathbf{t} 2=4)$. While not prevalent in the entire sample, some participants discussed the importance of conserving resources or taking care of the environment as ways to solve problems in India.

"Yes, I have done things to help my society that is keeping my society clean, not waste water." (Male, Age $14, \mathrm{t} 1$ )

"By planting trees and making aware of planting, which can make my society green..." (Male, Age 14, t2) 
Awareness/motivation/advising (not specified/everyone) $(\mathbf{t} 1=18, \mathbf{t} 2=20)$. Participants further explained how to solve problems in India through advising others (either unspecified or everyone) to care about injustices and think of solutions. In the following instances, participants did not make it clear whom they were targeting specifically in these problem-solving strategies.

"Yes, of course, I have a role in helping society. I have gone for many campaigning to make aware people about many diseases, history and caste system, discrimination." (Female, Age 13, t1)

"I can raise awareness among the people regarding different issues like gender discrimination etc." (Male, Age 13, t2)

Awareness/motivation advising (among privileged) $(\mathbf{t} 1=\mathbf{1 4}, \mathbf{t} 2=12)$. Similar to the previous theme, participants also explained how advising other privileged individuals about injustices and similar solutions would solve problems in India. In these instances, participants targeted those who were a part of the same social group or held the same level of privilege as they do.

"I helped my friends I told them to adjust in all the situation because we are living in a society where many people live." (Male, Age 13, t1)

"I should create awareness among others peoples also to help them. I should have requested the government to provide better means of education to the children. I would have organized programs to make my school aware of it. I would have helped them in any manner I can." (Male, Age 14, t2)

Awareness motivation/advising (among those facing problems) $(\mathrm{t} 1=12, \mathrm{t} 2=24)$. In this theme, participants described how they would advise and/or bring awareness to those currently facing identified problems (underprivileged) in India.

"I had done something in my past to help others like help the poor, like talking with them and tell them to send their children to school." (Male, Age 13, t1)

"Spreading awareness about the new programmes that have been implemented to help the underprivileged groups, starting a fundraising society that should be situated in their own locality to help them in their time of crisis, convincing more people to modernize themselves." (Male, Age 15, t2)

Overcoming discrimination through unity $(\mathbf{t} 1=11, \mathbf{t} 2=9)$. Finally, the last theme that emerged in the Strategies for Problem Solving domain explores participants' plans to overcome discrimination (one social injustice in India) through unity and interaction with one another. While this theme decreased in frequency post-field-trip intervention, participants consistently talked about coming together with both privileged and underprivileged groups to solve issues.

"I can also break the discrimination by playing games with them." (Male, Age 14, t1)

"We should discuss the problems by sitting together." (Female, Age 13, t2)

\section{Experiences of Helping}

The sixth domain reflects participant experiences of helping others. It covers how participants have used their own privilege to help people within various sections of their ecological system. It also encompasses participants' feelings about helping. 
Friends $(\mathbf{t} 1=\mathbf{1 4}, \mathbf{t} 2=\mathbf{4})$. In this theme, participants discussed their experiences in helping their friends, underclassmen, or carrying out household duties in the home. Specifically, they described instances in which they were able to solve problems on their own.

"Yes, I have helped others but very little of them. I helped my friend when he is in need." (Female, Age $15, \mathrm{t} 1)$

"Yes, I do have a role in helping society by helping mom by buying vegetables and helping her by cooking some food helping dad in the money matter I also use to help my small brothers and sisters in studies." (Male, Age 14, t2)

Family $(\mathbf{t} 1=\mathbf{1 0}, \mathbf{t} 2=\mathbf{1 1})$. Similar to the previous theme, participants discussed their experiences in helping their families or instances in which they were not able to help their family. This theme appears in similar frequency pre- and post- field-trip intervention.

"I am the eldest son, so I have to help my parents in many ways and of course my brother for his studies." (Female, Age 15, t1)

"My parents have a great role, but I don't have any role because I am not capable of helping them as I am not earning money." (Male, Age 15, t2)

School $(\mathbf{t} 1=\mathbf{0}, \mathbf{t} 2=3)$. In this theme, participants articulated how they would help others specifically in school. There was a small increase in participant identification of school-based helping post- field-trip intervention.

"Yes, I have donated a few of my things to the poorer society and participated in the activities to help the poor through my school." (Male, Age 16, t2)

Evaluative feelings and reflections $(\mathbf{t} 1=15, \mathbf{t} 2=11)$. Some participants shared their personal feelings and reflections when discussing their experiences with and reactions towards social injustice. There was a decrease between pre- and post- field-trip intervention within this particular theme.

"We have also arranged so many festivals to feed the poor people. It makes me feel good, and it satisfies me." (Male, Age 13, t1)

"The most unfair thing in our society is gender discrimination. For me, it's hard to tolerate if I see." (Female, Age 14, t2)

\section{Reasons for or Barriers to Problem Solving}

The seventh and final domain explored reasons it is crucial to solve social injustices while labeling the barriers to most solutions. Participants described themes that related to both internal and external motivators to problem-solving, such as the duty to their nation, a responsibility they hold, and for simple external needs.

Reasons for solving problems - duty/responsibility/should $(\mathbf{t} 1=\mathbf{1 9}, \mathbf{t} 2=\mathbf{2 2})$. This theme explored participants' expressed interest in solving problems because it was their duty or responsibility as a member of society. This theme increased post-field trip intervention as participants described their duty as a new generation that shares the world with less privileged individuals.

"Every individual has a role to play in society without which any society could go off balance. Every role is in one way or the other interrelated." (Male, Age 16, t1) 
"I have a major role in helping my society because it today's modern world the young, energetic children are responsible for the upcoming generations." (Male, Age 15, t2)

Reasons for solving problems - progress of nation $(\mathbf{t} 1=\mathbf{1 0}, \mathbf{t} 2=12)$. Similar to the previous theme, the participants described how they must solve problems because it would help improve India. Some participants described the needs of the country and how their own identity also indicated their need to help the nation improve.

"Yes, I do have a role in helping the society as a good citizen I could help my society to be the best because I love my society and the people of the society those who help each other." (Female, Age 15, t1)

“As I am an Indian, I will try to progress India." (Female, Age 14, t2)

Reasons for solving problems - self $(\mathbf{t} 1=4, \mathbf{t} 2=3)$. Participants described the reasons they want to solve problems as a way to receive personal benefits in the future. The presence of this theme slightly decreased between pre and post-field trip intervention.

"If we help them little but also they will be very happy and pray for us." (Male, Age 13, t1)

"If we help them those are being ragged by seniors they would also help us in our needy time" (Male, Age 15, t2)

Barrier - not able to help $(\mathbf{t} \mathbf{1}=\mathbf{1 1}, \mathbf{t} \mathbf{2}=\mathbf{1 5})$. Lastly, this theme articulated the reasons participants do not engage in helping others or feel that the responsibility lies with someone else. This theme increased from pre- to post-field trip intervention.

"I haven't helped. Actually, I never realized that there are people who really suffer from so many things." (Female, Age 15, t1)

"I do have many roles in helping society, but sometimes it's either not the right place or not the right time." (Female, Age 15, t2)

\section{Discussion}

This study aimed to investigate how socioeconomically privileged students at a private high school in India understood social issues in their communities. Specifically, it explored whether their qualitative understanding of and discourse about working against social and economic oppression changed after they took a field trip to a nearby under-resourced village.

In India, privilege is not only based upon economic wealth and social class, but also on one's caste, a hereditary social organization of occupation and status (Bhattacharyya, Woods, \& Lykes, 2017; Thorat \& Neuman, 2012). As privilege is embedded within the social stratification of India, privileged Indian youth have a unique role in their communities as future leaders and can be the change agents in combating systemic injustices. While social injustices like mass poverty (Mehta et al., 2011) and corruption (Pring, 2017) are embedded in everyday aspects of Indian society, desensitization is a barrier to building insight into social injustices (Heybach, 2015). Indian youth are surrounded by these injustices but are not required to examine them in their daily lives. The field trip intervention in this study was a method to break through patterns of desensitization to increase social justice awareness. The qualitative findings based on the participants' perspectives following the field trip intervention are discussed below. 
Seven domains from participants' written reflection prompts pre and post field trip intervention revealed youth's attitudes towards and perspectives of social justice issues in India. Positionality codes about how youth aligned themselves in relation to those they identified as affected by social issues stayed relatively constant before and after the field trip, suggesting that positionality may be more innate and harder to shift through a one-time intervention. The Discrimination domain included seven forms of discrimination participants viewed in society on the basis of caste, gender, religion, economics, age, sexual orientation, and general unspecified discrimination. Caste, gender, age, and economic discrimination slightly decreased post field trip, perhaps because they were not overtly present during the field trip. Otherwise, forms of discrimination discussed stayed relatively stable pre and post field trip. Discussion of Structural Issues increased after the field trip, with the exception of crimes. Participants described systemic access to basic needs such as clean water or education and structures responsible for these issues -- such as the government and the law. A fourth domain, Village Level Issues, were mostly present post field trip, as it reflected topics participants discussed specific to the village they visited. The final three domains were about how participants understood how to help and solve the very problems in society they discussed. Strategies for Problem Solving reveals diverse ways youth consider to address social issues. They include giving and donating, creating access to structural opportunities, access to literacy and educational opportunities, increasing conservation and environmentalism, overcoming discrimination through unity, and raising awareness of issues among the privileged and those facing injustice. Participants' discussion of access to structural opportunities and access to education as solutions increased after the field trip, reflecting an increased awareness of the structural level of injustice. Raising awareness among those who face problems also increased after the field trip, potentially indicating a perceived responsibility, lack of knowledge, and attribution of the agency of those who face injustice after meeting with these very people. Giving/donating, increasing awareness among the privileged and overcoming discrimination through unity decreased slightly post-field trip. Experiences of Helping reflected participants' descriptions of helping their friends, family, and people in school, including emotions participants described experiencing while helping. Themes in this domain stayed relatively constant pre and post field trip, with a decrease, however, in participants discussing experiences of helping friends and their emotions associated with helping after the field trip. The final domain, Reasons for or Barriers to Problem Solving, described participants' reasoning for solving social issues which ranged from benefits to the self, the progress of the nation, a sense of duty toward society, and barriers to helping such as not having the time or needing to do their schoolwork. The progress of the nation and duty toward society as reasons to help increased post-field trip as did identification of barriers to problem-solving.

In further organizing the themes that emerged from this study, the social-ecological framework can be used for more in-depth insight into Indian youth's perspectives on social issues. In this framework, social justice endeavors can be characterized as occurring at three distinct levels: (a) work addressing the needs of individuals and families operating at the micro level; (b) work with communities and organizations operating at the meso level; and (c) work to influence existing social structures, ideologies and policies operating at the macro level (Bronfenbrenner, 1979; Goodman et al., 2004). Consistent with previous studies which explored social justice awareness through school-based initiatives (Ashley, 2006; Choi et al., 2015; Cordero \& Rodriguez, 2009), this study's results indicated an increased understanding of social justice issues and solutions across micro, meso, and macro levels, prominently the latter two.

For example, increases in the codes such as Lack of Systemic Resources and Access to Structural Opportunities post-intervention reflect sample-level changes in the number of participants who displayed an awareness of meso- and macro-systemic levels of oppression and awareness of how systems need to change to remove structural barriers for the marginalized. More specifically, participants' direct experiences of people who lacked access to jobs, medical care, water, and electricity appeared to contribute to students' awareness of meso- and macro-level systemic challenges facing Indians living in rural and impoverished areas. Relatedly, after 
the field trip, participants cited meso- and macro-level strategies of helping, including improving access to such structural resources as employment, health services, and legal rights. While some students did describe microlevel issues (e.g., interpersonal caste discrimination or gender discrimination), participant responses following the field trip reflected a more nuanced understanding of meso- and macro-level social injustices and avenues to address them than earlier responses had. For example, a higher frequency of participants post-intervention referred to groups of people not having access to Human Rights, a macro-level issue.

Multiple codes decreased pre- to post-intervention, most prominently Crimes, where participants described stealing, murdering, and kidnapping as a problem in society; Experiences of Helping, where participants described their own experiences of personally helping others; and Helping Friends and Family, where participants discussed helping their friends and family as a solution to social injustice. These decreases reflect that youth's preconceived notions and understanding of issues changed after the field trip and that with deeper insight following a direct experience with impoverished people, these micro-level issues and strategies seemed less relevant or practical. A higher frequency of participants post-intervention described a solution to social injustice as raising Awareness and Motivation Among those Facing Problems. After meeting people who lived in poverty, participants may have seen greater value in working to increase awareness of social injustice among those who experience it, though, this may reflect their understanding that the marginalized were responsible for their living conditions and place in society. Consistent with the previous literature on immersion outcomes (Choi et al., 2015; Cordero \& Rodriguez, 2009), participants in the current study examined their own role in relation to the social justice issues they witnessed and strategies to solve these issues. However, the frequency changes reported in this study are solely changes in qualitative data counts so they must not be over-interpreted.

The field trip intervention's impact on changes in the frequencies of the obtained codes can be useful when observing the effect of educational interventions on privileged youth's consciousness building. Educational interventions are a useful approach in increasing the likelihood that privileged groups will engage in advocacy and activism with and for the oppressed (Bhattacharyya, Woods, \& Lykes, 2017; Perrin et al., 2013). In addition to greater social benefits, engagement in social-justice interventions benefit young people in personal development, increased career opportunities, confidence, prosocial behavior (Brudney \& Schmahl, 2010), selfesteem, and social responsibility (Wade, 2011). While the benefits of immersion trips are evident, there are limited immersion options for youth in India (e.g., high school students), possibly due to safety concerns of long-term immersion trips for this population. A field trip intervention may facilitate the early stages of ally development, such as how privileged youth think about poverty and privilege.

Overall, the current findings suggest that the Indian youth in the study thought thematically differently after paying attention to conditions in an under-resourced village in their community. A fundamental tenet in liberation psychology, conscientization (Martín-Baró, 1996), calls psychologists to help society learn how to "perceive social, political, and economic contradictions and to take action against the oppressive elements of reality" (Freire, 1970, p. 35). More specifically, liberation psychology focuses its efforts on raising the consciousness of the oppressed to analyze the situations contributing to their marginalization (Lykes \& Sibley, 2014). Based on the findings from this study, a field trip may be one practical step in transforming the consciousness of youth in India who may experience oppression in the wider global community but hold relative privilege in their Indian context.

\section{Limitations and Future Research}

Participants in this study reported that they had never gone on a field trip of this nature before nor had they ever participated in a psychological study, so generalizing these findings must be done with appropriate caution. In the Indian school context, students are rarely asked their opinions on their relationship with their broader community and the social issues that surround them. Expressing their opinions and writing down 
their self-reflections were new practices for these participants. This novelty may have influenced the depth and elaboration of their reflection. Handwritten data also can be limiting in assessing areas of perceptual change, which interviews may have been better able to capture. Additionally, the balance of gender and religion in the sample was skewed due to the high enrollment of males and hindus in the school. Futures studies should be conducted with more female and religiously diverse participants, participants for whom such practices are not novel, or should be conducted over an extended period of time so as to familiarize participants with the process of research and expressing opinions.

Without the collaboration with village leadership in the design of the immersion intervention and proper follow-up with schools, this study could be read as promoting "poverty tourism." Immersion interventions need to be thoughtful, sustainable and mutually beneficial, deliberate in promoting collaborations with local village leaders and should take the needs and comfort of the villagers into consideration first and foremost. Witnessing injustice coupled with critical self-reflection can inspire those with the privilege to be concerned about oppressive conditions, however, witnessing injustice alone can lead to poor villages such as the one involved in the current study being exploited in new ways. Educating the privileged is not the burden of those who are most adversely impacted by unjust systems, especially when that education can deplete local resources further, or lead to a sense of shame among those facing poverty. Resourced schools can listen to the needs and desires of villages with whom they collaborate and can respond to their requests for resources or advocacy. Furthermore, the perspectives of the youth living in the village targeted in the current project could be explored in future studies, including the perceptions of marginalized, "lower-caste," or Dalit youth about social oppression and social change.

Regarding researcher-participant dynamics, the first-author and field researcher has a South Asian, Bengali-U.S. background and interacted with the participants extensively, which may have inadvertently created a demand characteristic and influenced how the student participants responded to the questions they were asked. Participants may have wittingly or unwittingly provided answers that they thought were desired by the researcher or perhaps they did the opposite, providing answers that challenged their perceptions of the first author's desired answers. Future studies aiming to minimize this should vary the data collectors, minimize researcher-participant interactions, or integrate the researcher as a participant-observer.

Building on this research could contribute necessary scholarship to the field of counseling and psychology. This study took a step in developing and refining categories of privileged Indian youth's reflections both before and after exposure to an under-resourced village. Future research can build on these results by developing a scale to assess young Indians attitudes and beliefs regarding social and economic injustice in India. This scale would facilitate future research, inform future interventions, and assess the effectiveness of interventions with a contextually relevant tool. Future studies also could target a more in-depth examination of the constructs reflected in the current participants' responses, such as caste discrimination, reasons for wanting to solve problems, and which factors contribute to or affect their beliefs. Further, long-term effects of immersion trips on Indian students' attitudes, beliefs, and behaviors (including changes in their career trajectories) could be assessed to inform school-based interventions.

\section{Implications and Conclusions}

This study can have implications for developing interventions with economically privileged Indian students that could facilitate their awareness of social injustice and, perhaps, their greater intentionality to address it when they see it. On an individual level, reflecting on experiences with impoverished people and on the importance of helping others can facilitate privileged Indian youth's development of a deeper understanding of social oppression. At the local school level, educators can take Indian students on field trips to spend extended 
time in conversation with under-resourced communities, to develop their awareness of social issues and to inspire students to use their privilege to serve as advocates for the marginalized. On a national level in India, socio-economically privileged schools can be encouraged to incorporate field trips into their curriculum to provide students exposure to social issues impacting people in their country. Research on Indian youth's social justice engagement may be able to inform interventions that leverage privilege to reduce oppression beyond India, as well. At a global level, investing in future local stakeholders of power (e.g., youth in developing nations) may produce local avenues for social change and may reduce dependence on international aid in overcoming global social issues.

\section{Author Contact Information}

Please address correspondence about this article to Sriya Bhattacharyya, Boston College, 140 Commonwealth Ave., Chestnut Hill, MA 02467. Email: bhattasr@bc.edu.

\section{Acknowledgments}

We would like to acknowledge the Orbis Institute in Denver, Colorado for supporting this research. Additionally, this research would not have been possible without support and resources from KiiT International School and KiiT University in Bhubaneswar, India. Finally, we extend our gratitude to the participants in this study who opened their hearts and minds to those suffering from injustice in their communities. 


\section{References}

Acharya, R., Singh, A., Santhya, K.G., Ram, F., Jejeebhoy, S., Ram, S., \& Mohanty, S. (2010). Participation in civil society and political life among young people in Maharashtra: Findings from the youth in India - Situation and needs study. Journal of Adolescence, 33(4), 553-561. doi:10.1016/j. adolescence.2009.05.012

Ashley, L.D. (2006). Inter-school working involving private school outreach initiatives and government schools in India. Compare: A Journal of Comparative Education, 36(4), 481-496. http://dx.doi. org/10.1080/03057920601024941

Bhattacharyya, S., Woods, M., \& Lykes, M.B. (2017). Can educational policy redress historical discrimination? Exploring a university community's experiences with India's caste-based affirmative action policy. Community Psychology in Global Perspective, 3(2), 38-59.

Bowman, N.A., Brandenberger, J.W., Mick, C.S., \& Smedley, C.T. (2010). Sustained immersion courses and student orientations to equality, justice, and social responsibility: The role of short-term servicelearning. Michigan Journal of Community Service Learning, 17(1), 20-31. Retrieved from https://files. eric.ed.gov/fulltext/EJ950763.pdf

Bronfenbrenner, U. (1979). The ecology of human development: Experiments by nature and design. Cambridge, MA: Harvard University Press. http://dx.doi.org/10.4324/9780203278130 chapter 8

Brudney, J. L., \& Schmahl, S. (2010). Service learning: Findings from a 14 nation study. Journal of Nonprofit \& Public Sector Marketing, 20(1), 6. doi:10.1080/10495141003702332

Case, K. A. (2013). Beyond diversity and whiteness: Developing a transformative and intersectional model of privilege studies pedagogy. In K. A. Case (Ed.), Deconstructing privilege: Teaching and learning as allies in the classroom (pp. 1-14). New York, NY: Routledge.

Charmaz, K. (2014). Constructing Grounded Theory (2nd ed.). Thousand Oaks, CA: Sage Publications Ltd. doi: $\underline{10.1177 / 14687941070070040802}$

Choi, K. M., VanVoorhis, R. W., \& Ellenwood, A. E. (2015). Enhancing critical consciousness through a crosscultural immersion experience in South Africa. Journal of Multicultural Counseling and Development, 43, 244-261. http://dx.doi.org/10.1002/jmcd.12019

Cordero, A., \& Rodriguez, L. N. (2009). Fostering cross-cultural learning and advocacy for social justice through an immersion experience in Puerto Rico. Journal of Teaching in Social Work, 29(2), 134-152. doi: $10.1080 / 08841230802238195$

Downe-Wamboldt, B. (1992). Content analysis: Method, applications, and issues. Health Care for Women International, 13, 313-321.

Elo, S. and Kyngas, H. (2007) The Qualitative Content Analysis Process. Journal of Advanced Nursing, 62, 107115.

Freire, P. (1970). Pedagogy of the oppressed. New York: Continuum.

Goodman, L.A., Liang, B., Helms, J. E. Latta, R.E., Sparks, E., \& Weintraub, S.R. (2004). Training counseling psychologists as social justice agents: Feminist and multicultural principles in action. The Counseling Psychologist, 32, 793-837. doi:10.1177/0011000004268802

Heybach, J.A. (2015). Learning to feel what we see: Critical aesthetics and "difficult knowledge" in an age of war. Critical Questions in Education, 3(1), 23-34. 
Hsieh, H. F., \& Shannon, S. E. (2005). Three approaches to qualitative content analysis. Qualitative Health Research, 15(9), 1277-1288.

Ilavarasan, P.V. (2013). Community work and limited online activism among India youth. The International Communication Gazette, 75(3), 284-299. doi:10.1177/1748048512472945

International Development Research Center. (2007). Emerging donors in international development assistance: The India case. Retrieved from https://www.idrc.ca/sites/default/files/sp/Documents\%20EN/Case-ofIndia.pdf

Jessop, T.S. (2001). Key ingredients in the search for social justice: A case study of best practice in a Calcutta school. Catholic Education: A Journal of Inquiry and Practice, 5(1), 101-116. Retrieved from http:// digitalcommons.lmu.edu/ce/vol5/iss1/8

Lykes, M. B., \& Sibley, E. (2014). Liberation psychology and pragmatic solidarity: North-South collaborations through the Ignacio Martín-Baró Fund. Peace and Conflict: Journal of Peace Psychology, 20(3), 209-226. doi: $10.1037 / \mathrm{pac} 0000045$

Martín-Baró, I. (1996). Writings for a liberation psychology: Ignacio Martín-Baró (A. Aron \& S. Corne, Eds.). Cambridge, MA: Harvard University Press.

McIntosh, P. (1988). White privilege and male privilege: A personal account of coming to see correspondences through work in women's studies. Wellesley, MA: Wellesley College, Center for Research on Women.

McLellan, J.A. \& Youniss, J. (2003). Two systems of youth service: Determinants of voluntary and required youth community service. Journal of Youth and Adolescence, 32(1), 47-58. doi:10.1023/A:1021032407300

Mehta, A. K., Shepherd, A., Bhide, S., Shah, A., \& Kumar, A. (2011). India chronic poverty report: Towards solutions and new compacts in a dynamic context. New Delhi: Indian Institute of Public Administration.

Moane, G. (2003). Bridging the personal and political: Practices for a liberation psychology. American Journal of Community Psychology, 31, 91- 101. doi:10.1023/A:1023026704576

Morrow, S. L. (2005). Quality and trustworthiness in qualitative research in counseling psychology. Journal of Counseling Psychology, 52, 250-260. doi: $\underline{10.1037 / 0022-0167.52 .2 .250}$

Panwar, M., Mathur, D., Chand, G., Dkhaka, M., Singh, R. R., \& Moxley, D. P. (2014). Action learning in the Indian village as an alternative to the traditional field practicum in the foundation year of the MSW. Social Work Education, 33(8), 984-997. doi:10.1080/02615479.2014.921285

Perrin, P.B., Bhattacharyya, S., Snipes, D. J., Hubbard, R. R., Heesacker, M., Calton, J.M.,...\& Lee-Barber, J. (2013). Teaching social justice ally development among privileged students. In K. A. Case (Ed.), Deconstructing privilege: Teaching and learning as allies in the classroom (pp. 49-62). New York, NY: Routledge.

Pring, C. (2017). People and corruption: Citizens' voices from around the world. Transparency International. ISBN:978-3-96076-067-2

Sharma, A. (2014). India votes: A Modi landslide. New Zealand International Review, 39(4). Retrieved from http://www.highbeam.com/doc/1G1-376852492.html

Strauss A. \& Corbin, J. M. (1998). Basics of qualitative research: Techniques and procedures for developing grounded theory. Newbury Park, CA: Sage.

Thompson-Miller, R. \& Feagin, R. (2007). Continuing injuries of racism: Counseling in a racist context. The Counseling Psychologist, 35, 106-115. doi: 10.1177/0011000006294664 
Thorat, S. \& Neuman, K.S. (2012). Blocked by caste: Economic discrimination in modern India. New Delhi: Oxford University Press. ISBN: 9780198081692

Yeh, C. J. \& Inman, A. G. (2007). Qualitative analysis: Strategies for best practices. The Counseling Psychologist, 35, 369-403. doi: 10.1177/0011000006292596

Wade, R. (2011). Service for learning. Educational Leadership, 68(8), 28-31. 